\title{
Under nutrition in diarrhoea affected under-five children
}

\author{
Manjeeta. ${ }^{1}$, Vikramaditya B. ${ }^{2 *}$, Shankar Joshi H. ${ }^{3}$, Kumar Jha A. ${ }^{4}$ \\ DOI: https://doi.org/10.17511/ijphr.2019.i3.04
}

\footnotetext{
1 Manjeeta, Junior Resident, Department of Community Medicine, SMMH Government Medical College, Saharanpur, Uttar Pradesh, India.

${ }^{2 *}$ Bibhava Vikramaditya, Assistant Professor, Department of Community Medicine, SMMH Government Medical College, Saharanpur, Uttar Pradesh, India.

3 Hari Shankar Joshi, Professor and Head, Department of Community Medicine, SMMH Government Medical College, Saharanpur, Uttar Pradesh, India.
}

${ }^{4}$ Amit Kumar Jha, Professor, Department of Community Medicine, SMMH Government Medical College, Saharanpur, Uttar Pradesh, India.

Introduction: In India the vicious cycle between diarrhea and undernutrition has not yet been broken. Undernutrition predisposes to infection of gastro-intestinal system. Once the child suffers from undernutrition it is very difficult to come out of this vicious cycle. Objective: The study was done to study the social profile and risk factors of diarrheal diseases in under-five children. Methods: The study was carried out on hundred under five year old diarrhea cases in rural area of Saharanpur from September to December 2018. The social, cultural, economic and environmental factors were recorded along with physical measurements by house to house visits on pretested and suitably modified proforma. The analysis was done using MS Excel software and EPI Info. Results: Among them sixty one children were found to be suffering from undernutrition. The undernourished children had also suffered greater number of times from respiratory tract infections and diarrhea in the past one year. Overcrowding was observed in majority of the houses. Diarrhea was observed to be more in children of illiterate mothers and lower socio-economy groups. The process of giving oral rehydration therapy and home available fluids was found to be faulty in majority of households. Conclusion: Providing additional nutrition to undernourished children, proper use of oral rehydration therapy and home available fluids should be explained to mothers. The risk factors identified for diarrhea like bottle feeding, lack of hand washing and unhealthy food hygiene practices can be avoided by health education of the mothers in resource-poor health care setting.

Keywords: Diarrhea, undernutrition, Under-five, Saharanpur

\section{Corresponding Author}

Bibhava Vikramaditya, Assistant Professor, Department of Community Medicine, SMMH Government Medical College, Saharanpur, Uttar Pradesh, India.

Email: vikramadityabibhav@gmail.com
How to Cite this Article

Manjeeta, Vikramaditya B, Joshi HS, Jha AK. Under nutrition in diarrhoea affected under-five children. Public Health Rev Int J Public Health Res. 2019;6(3):119-125.

Available From

https://publichealth.medresearch.in/index.php/ijphr/ article/view/109
To Browse

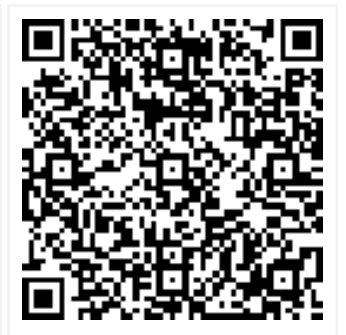

Manuscript Received 2019-06-10

Conflict of Interest No

Review Round 1
2019-06-20
Funding
Nil

2019 by Manjeeta, Bibhav.

hava Vikramaditya, Hari Shankar Joshi, Am This is an Open Access article licensed under ar Jha and Published by Siddharth Health Research icense https://creativecommons.org/licenses/by/4.0/ unported [CC BY 4.0]. 


\section{Introduction}

Diarrheais defined as defecation frequency of three or more loose/ liquid stools in a day [1]. Diarrheamost often results from the ingestion of pathogens from faeces that have not been disposed of properly or from the lack of hygiene. Diarrheain under five year old children forms the third most common cause of death, accounting for $13 \%$ deaths in this age group [2].

In India the vicious cycle between diarrhea and under-nutrition, poor environmental sanitation, over crowding, improper excreta disposal, contaminated drinking water, ignorance towards oral rehydration therapy all have contributed in making diarrhea a significant public health problem.

Undernutrition is one of the most important underlying cause of morbidity and mortality in under five year old children in India as they are the most vulnerable to its effect because of rapid growth. Diarrheal diseases are very important cause of undernutrition in children under five years old. Diarrhea can lead to undernutrition and undernutrition can predispose todiarrhea.

Each episode of diarrhea deprives the child of nutrition necessary for growth. Severe undernutrition coincides with the age at which babies are usually weaned. Susceptibility to infection and severity of illness are greater in undernourished than well nourished [3]. Undernourished children are thus affected by diarrheawhich is further detrimental to their nutritional status.

Diarrhea incidence remains a tremendous burden on children in low and middle income countries [4]. Prevalence of diarrhea and undernutrition among children in low socioeconomic areas are high, not only because children and their parents are exposed to the environmental factors that cause diarrhea such as unsafe water, poor hygiene and sanitation, but also due to poor food hygiene practice.

Bacterial diarrheal infection is more common in severe and complicated undernutrition and thought to occur in part due to the loss of the protective mucosal barriers in the gastrointestinal tract [5]. Oral rehydration therapy (ORT) with oral rehydration salt (ORS) solution is the most effective case management of diarrheal dehydration and prevents diarrheal deaths in children.But still ORT usage rates are inadequate in the community [6-7].
The present study was undertaken to cover the social, environmental and medical aspects associated with diarrhea for aiding in better planning and organisation of health services as well as preventive measuresin the rural population.

\section{Aim and Objectives}

Aim:To evaluate the social factors and nutritional status of diarrhea affected under five children.

\section{Objectives}

01. To assess the social, economical and environmental factors related to diarrhea.

02. To assess the nutritional status of under five children with diarrhea.

03. To know the knowledge, attitude and practice (KAP) of administering oral rehydration therapy by the mothers of diarrhea affected children.

\section{Material and Methods}

Study Setting: The study was conductedin ruralfield practice area of Department of Community Medicine, SMMH Government Medical College, Saharanpur.

The children from villages Pilkhani and Goshipura, Block Rampur Maniharan, District Saharanpur were included in the study. The period of study was from September to December 2018 (three months).

Study design: The present study was a cross sectional study. Interviews were conducted by house to house visits.

Sampling method: Two villages were randomly chosen among all villages in ruralfield practice area of Department of Community Medicine, SMMH Government Medical College. Children selected for the study belonged to age group of newborn to 5 years, who are mostly permanent resident of this area.

With the help of field workers the homes were identified with diarrhea affected children. Only those children were selected who had diarrheal episode in the last one month. A total of 100 under five year age children affected with diarrhea were included in the study.

Ethical consideration and permission: Informed written consent was taken from guardian of all children after explaining to them the purpose of the study. Privacy of the guardian and children were maintained. 
The study was duly approved by the Institutional Ethics Committee of SMMH Government Medical College, Saharanpur.

\section{Inclusion criteria}

01. Under five children with diarrheal episode in the last one month.

02. Those children with guardianswilling to participate in the study.

\section{Exclusion criteria}

01. Refusal to participate.

Procedure of data collection:A list of the houses with children affected with diarrhea was made with help of field workers. The data was collected by house to house visit by the investigators. A pretested and suitably modified proforma was used to record all relevant data on various associated social, cultural, economic and environmental factors by interviewing the mother of the child. Socio economic status was worked out as per Modified Udai Pareek (MUP) scale as the study was in rural area. Based on the MUP score, the SES was divided into 4 categories.

The child's physical parameters were recorded and nutritional status was seen. After the end of the interview and data collection in each house the process of administering Oral Rehydration Salt (ORS) and Home Available Fluids (HAF) to the Diarrhea cases was explained and practically demonstrated to the members of household by the investigator.

Development of proforma: The proforma was an interview questionnaire that was developed with assistance from senior faculty members of Department of Community Medicine, SMMH Government Medical College, Saharanpur. The proforma consisted of six sections:

01. General Information

02. Modified Udai Pareek scale (MUP).

03. Socio Demographic Information.

04. History and risk factors of diarrhea.

05. Behaviour and food hygiene and Oral Rehydration Therapypractices at household level.

06. Anthropometric measurements.

A pilot study was done on 25 childrenaffected with diarrheain another village other than the villages selected to check the comprehensibility and acceptability of the proforma.
Necessary changes were made after the pilot study.

Statistical methods and analysis: Data was tabulated and analysed using MS Excel software and Epi Info. Percentage and Chi square test was used to analyze epidemiological variables.Two-tailed $p$ value less than 0.05 was considered significant.

\section{Results}

Since the total cases were 100 so the percentage in each column was equal to the number of children.

Table-1: Distribution of diarrhea cases according to socio-economic status

\begin{tabular}{|l|l|l|l|}
\hline Socio-economic class & Male children & Female children & Total \\
\hline Low & 10 & 8 & 18 \\
\hline Low middle & 36 & 28 & 64 \\
\hline High middle & 6 & 8 & 14 \\
\hline High & 2 & 2 & 4 \\
\hline Total & 54 & 46 & 100 \\
\hline
\end{tabular}

Out of 100 children 54 were male and 46 were female.

As per Modified Udai Pareek scale the Socioeconomic distribution showed thatmajority of cases (82\%) came from lower socio-economic class i.e. low middle (64\%) and low socio-economic class $(18 \%)$.

Table-2: Distribution of diarrhea cases according to Literacy status of mother.

\begin{tabular}{|l|l|}
\hline \multicolumn{1}{|c|}{ Literacy status of mother } & No of children \\
\hline Illiterate & 39 \\
\hline Primary & 30 \\
\hline Middle & 15 \\
\hline Secondary & 10 \\
\hline Higher Education & 7 \\
\hline
\end{tabular}

The above table revealed that the incidence of diarrheais inversely proportional to literacy status of the mother.

Maximum cases were in children of Illiterate mothers (39\%) which decreased as the number of years of schooling increased.

Table-3: Distribution of diarrhea cases according to overcrowding and undernutrition

\begin{tabular}{|l|l|l|}
\hline & \multicolumn{1}{|c|}{ Present } & \multicolumn{1}{c|}{ Not present } \\
\hline Overcrowding & 68 & 32 \\
\hline Undernutrition & 61 & 39 \\
\hline
\end{tabular}

Overcrowding (68\%) and undernutrition (61\%) were seen in majority of children with diarrhea. 
Table-4: Previous episodes of Diarrhea and Acute respiratory infections within 1 year in normal and undernourished children.

\begin{tabular}{|l|l|l|l|l|}
\hline \multirow{2}{*}{} & \multicolumn{2}{|c|}{ Diarrhea episodes } & \multicolumn{2}{c|}{ ARI episodes } \\
\cline { 2 - 5 } & $\begin{array}{l}\text { Presentnumber } \\
(\%)\end{array}$ & $\begin{array}{l}\text { Absentnumber } \\
(\%)\end{array}$ & $\begin{array}{l}\text { Presentnumber } \\
(\%)\end{array}$ & $\begin{array}{l}\text { Absentnumber } \\
(\%)\end{array}$ \\
\hline $\begin{array}{l}\text { Normal } \\
\text { nourished }\end{array}$ & $8(20.51)$ & $31(79.49)$ & $6(15.39)$ & $33(84.61)$ \\
\hline $\begin{array}{l}\text { Under- } \\
\text { nourished } \\
\text { children }\end{array}$ & $55(90.16)$ & $6(9.84)$ & $49(80.33)$ & $12(19.67)$ \\
\hline & $\times 2=46.56, p=0.00$ & $x 2=37.96, p=0.00$ \\
\hline
\end{tabular}

Previous episodes of diarrheawere present in majority $(90.16 \%)$ of undernourished children while only in one fifth (20.51\%) of normal nutritional status children. The difference was statistically significant.

Undernourished children had suffered significantly more from episode of acute respiratory infection in the past one year than their normal nourished counterparts.

Table-5: Unhealthy behaviour and food hygiene practices at household level.

\begin{tabular}{|l|l|}
\hline \multicolumn{1}{|c|}{ Unhealthy behaviour and practice } & No of Houses \\
\hline Bottle fed babies & 15 \\
\hline Unclean/Soiled/Unwashed hands & 68 \\
\hline Flies on uncovered food & 59 \\
\hline Contaminated drinking water & 42 \\
\hline Unclean Utensils & 61 \\
\hline
\end{tabular}

Due to presence of multiple unhealthy behaviour and practice in most of the houses the total percentage in above table is more than 100 .

Bottle feeding was seen in $15 \%$ of children. Hand washing practices were unsatisfactory in majority of houses $(68 \%)$.

It was seen that in large number of houses there was no provision of clean drinking water. Food hygiene was compromised by flies (59\%) and unclean utensils (61\%) in majority of houses.

Table 6: Distribution of procedure of administering ORT (Oral Rehydration Therapy) and HAF (Home Available Fluids) to the Diarrhea cases by the mother

KAP (knowledge, attitude, practice) of mothers of children

\begin{tabular}{|l|l|l|l|}
\hline Knowledge of ORT & 64 out of 100 & Knowledge of HAF & 52 out of 100 \\
\hline Attitude towards ORT & 31 out of 64 & Attitude towards HAF & 20 out of 52 \\
\hline Practice of ORT & 21 out of 31 & Practice of HAF & 20 out of 20 \\
\hline
\end{tabular}

The present study brought out that only $64 \%$ of mothers of cases had knowledge about Oral Rehydration Therapy and out of them only one third were practicing it. Almost similar scenario was seen with Home Available Fluids.

\section{Discussion}

The present study population consisted of 100 children under the age of 5 years affected by diarrhea. In the present study $54 \%$ male and $46 \%$ female children participated.

Study conducted by Durairajet al. among diarrhea affected children in Chennai, Tamil Nadu observed male children (55.71\%) to be slightly more affected than female children (44.29\%) [8].

Study conducted in 370 under five children in Nemam Tiruvallur district of Tamil Nadu in 2012 by Samyaet al. had $51.1 \%$ males and $48.9 \%$ females[9]. However, study conducted by Gupta et al.in slums of Bankura, West Bengal in 2015 had slightly higher prevalence of diarrhea in females $(22.89 \%)$ than males $(21.73 \%)$ [10].

Similar pattern was reported in the South Indian study by Stanly et al. where female children had slightly higher prevalence of acute diarrhea (23.8\%) than males $(21.4 \%)$ but the difference was not statistically significant [11].

Another study by Shah et al. in less than three year children in rural Sindh, Pakistan reported marginally higher diarrhea prevalence in girls than boys [12].

The reason may be socio cultural influence in these regions by which the nutrition of female children is neglected, limiting their access to health. No gender difference in the prevalence of diarrhea was seen inNational Family Health Survey -3 (NFHS-3) and NFHS-2[7, 13].

In the present study, themajority of cases (82\%) belonged to lower socio-economic class. This may be due to varied medical social factors in lower socio-economic class such as ignorance, lack of health education, overcrowding, poor hygiene, undernutrition, illiteracy etc.

Similar findings were seen in study by Mutaliket al. in Kasegaon, Maharashtra [14]. Kumaret al. in their cross section study of 200 cases of age ranging from 0 - 5 years having diarrhea at Kalyanpur, Bihar found Low Socio-economic status had greater impact over incidence of diarrhea [15]. 
The present study revealed that the incidence of diarrhea is inversely proportional to literacy status of the mother. This may be due to lack of health education and poor hygienic practices among illiterate mothers.Study by Shah et al. Reported higher prevalence of diarrhea was related with lack of education of mother [12]. Alelign et al. in cross sectional study in Debre Berhan Town, Ethiopia also found lack of maternal education as one of the main risk factors for diarrheal illness [16].

The present study observed overcrowding and undernutrition in majority of under-five children with diarrhea. Further these undernourished children had suffered significantly more from episode of diarrhea and acute respiratory infection in the past one year than their normal nourished counterparts.Study by Singh et al. on 3742 children at Kishanganj, Bihar in 2013 found higher incidence of diarrhea in children suffering from under nutrition [17].

Study by Gupta et al. found undernourished children had 14.4 times higher risk for acute diarrhea than normal children [10]. Study conducted by Durairajet al. also concluded that protein energy malnutrition was significant risk factors for the incidence of diarrhea [8]. Shah et al. in their study found low weight-for height as a factor related with higher prevalence of diarrhea [12].

In the present study unhealthy behaviour like bottle feeding andunhealthy food hygiene practices were present in the houses. Hand washing practices were unsatisfactory and clean drinking water was not available in majority of houses. Study by Gupta et al.found incidence of diarrhea higher in bottle fed children [10]. Study conducted by Durairajet al. concluded that unsafe drinking water was significant risk factors for the incidence of diarrhea [8].

Kumar et al. in their cohort study on 305 children below the age of six years atWardha, Maharashtra concluded provision of safe water supply to decrease diarrhea incidence [18]. Alelign et al.reported unsafe household storage of water and lack of hand washing after latrine usage to be main risk factor for diarrhea [16]. Study conducted by Kabhele et al. on 480 children between 6 and 59 months of age in Mwanza, Tanzania concluded not washing hands was associated with diarrhea [19].

Nwaohaet al. in their case control study on underfive children at Umuahia, Abia, Nigeria concluded diarrhea risk correlated with hand washing and sources and storage of water [20].
Musonda et al. in their case control study on 112 children at Ndola, Zambia also found that poor hand washing practice among parents was significantly associated with diarrhea [21].

The correct practice of administering ORT and HAF was found lacking in the rural community which tends to increase the severity and duration of diarrheain children. Study by Mutaliket al. also reported similar findings [14]. KAP of the community can be improved by explaining and practically demonstrating the process of administering Oral Rehydration Salt and Home Available Fluidsto the members of household.

\section{Limitations}

The study was undertaken in rural area of Saharanpur. Due to diversity and different living conditions in different part of country our findings cannot be generalized. The study could have been better if a larger sample with other risk factors like housing conditions, type of family, ventilation etc. were included.

\section{Conclusion}

Nutritional status of a child is an important factor which determines the recurrence of diarrheaand respiratory infections. Health education should be done for providing additional nutrition to undernourished children. Housing conditions should also be improved with correction of unhealthy behaviour and practices.

The process of administering ORT and HAF must be practically demonstrated to nursing mothers and made to be effectively practiced at home. It can be included as a part of school curriculum for wider awareness generation in future population.

The measures such as improvement of environmental sanitation, provision of clean drinking water, food hygiene, nutritional education, supplementary feeding and primary health care must be integrated for preventing episodes of diarrhea.

Recommendations: The process of administering ORT and HAF can be included as a part of school curriculum for wider awareness generation in future population. The risk factors identified for diarrhea like bottle feeding, lack of hand washing andunhealthy food hygiene practices can be avoided by health education of the mothers in resource-poor health care setting. 


\section{What this study adds in the existing knowledge}

The study would be a guide for further research in various part of country and would help health care personnel of Uttar Pradesh to plan approach for diarrhea prevention.

\section{Authors Contribution}

- Manjeeta worked in data collection and data tabulation.

- Bibhava Vikramaditya was principal investigator and wrote the manuscript.

- Hari Shankar Joshi guided in editing manuscript for corrections and proforma development and review.

- Dr. Amit Kumar Jha guided in finalization of manuscript andproforma development and review.

\section{Acknowledgements}

The authors thank the the local health workers and leaders for their support.

\section{Reference}

01. World Health Organization. The treatment of diarrhoea- a manual for physicians and other senior health workers, 4th rev. World Health Organization. 2005 [cited 2019 July 26].

Available from: [Article] [Crossref]

02. Million Death Study Collaborators. Causes of neonatal and child mortality in India- A nationally representative mortality survey. Lancet. 2010;376(9755)1853-60.

DOI:10.1016/S0140- 6736(10)61461-4 [Crossref]

03. Park K. Textbook of preventive and social medicine, Preventive medicine in Obstetrics, Paediatrics and Geriatrics. 25th ed, JabalpurBanarasidas Bhanot Publishers. 2019;p- 601. [Crossref]

04. Fischer Walker CL, Perin J, Aryee MJ, BoschiPinto C, Black RE. Diarrhea incidence in lowand middle-income countries in 1990 and 2010: a systematic review. BMC Public Health. 2012;12(1):220.

DOI: 10. 1186/1471-2458-12-220 [Crossref]
05. Brewster DR, Manary MJ, Menzies IS, O'loughlin EV, Henry RL. Intestinal permeability in Kwashiorkor. Arch Dis Child. 1997;76(3)236-41. DOI: $10.1136 /$ adc.76.3.236 [Crossref]

06. United Nations Children's Fund and Ministry of Health and Family Welfare, Government of India. Coverage Evaluation Survey 2009. All India Report, New Delhi- UNICEF. 2010 [cited 2019 July 26].

Available from: [Article] [Crossref]

07. International Institute for Population Sciences (IIPS) and Macro International. National Family Health Survey (NFHS-3), 2005-06 India. Volume-I, Mumbai-IIPS. 2007;Sep[cited 2019 July 26].

Available from: [Article] [Crossref]

08. Durairaj P, Raju S, Thirumalaikumarasamy S. Clinical profile and risk factors for persistent diarrhoea in children under five years of age in an urban referral centre. Int J Contemp Pediatr. 2017;4(6)1986-94.

DOI: $10.18203 / 2349-3291 . i j c p 20174156$ [Crossref]

09. Samya V, Stanly AM. Acute Diarrhea and Acute Respiratory Infection among Less than 5 Year Old Children- A Cross Sectional Study. Int J Sci Stud. 2015;3(7)149-153.

DOI: $10.17354 /$ ijss/2015/466 [Crossref]

10. Gupta A, Sarker G, Rout AJ, Mondal T, Pal R. Risk Correlates of Diarrhea in Children Under 5 Years of Age in Slums of Bankura, West Bengal. J Glob Infect Dis. 2015;7(1)23-29.

DOI: 10.4103/0974-777X.150887 [Crossref]

11. Stanly AM, Sathiyasekaran BW, Palani G. A population based study of acute diarrhea among children under 5 years in a rural community in South India. Sri Ramchandra J Med. 2009; 1(1)1-7.

[Crossref]

12. Shah SM, Yousafzai M, Lakhani NB, Chotani RA, Nowshad G. Prevalence and correlates of diarrhea. Indian J Pediatr. 2003;70(3)207-11. DOI: $10.1007 /$ bf02725583 [Crossref] 
13. International Institute of population Sciences (IIPS) and ORC Macro 2000. National Family Health Survey (NFHS-2), 1998-99- India. Mumbai- IIPS. 2000; Oct [cited 2019 July 26].

Available from: pdf [Article] [Crossref]

14. Mutalik AV, Raje VV. Relationship between maternal education and socioeconomic status on knowledge, attitude and practice of mother and her child regarding acute diarrhoeal diseases. Int J Community Med Public Health. 2017;4(12)4472-6.

DOI: $\quad 10.18203 / 2394-6040 . i j c m p h 20175155$ [Crossref]

15. Kumar M, Koram MR, Kumar L. Study of Various Causative Factors of Diarrhoeal Diseases with Special Reference to Bacteriological Profile among 0 to 5 Years Age Group. Int J Sci Stud. 2014;2(3)47-52.

[Crossref]

16. Alelign T, Asegidew W, Abera A. A Cross Sectional Study on the Incidence and Risk Factors of Diarrheal Illness among Children Under-five Years of Age in Debre Berhan Town, Ethiopia. J Health MedEcon. 2016;2(2)12.

DOI: $\quad 10.21767 / 2471-9927.100018$ [Crossref]

17. Singh JB, Kumar M, Shahnawaz K, Krishna A. Diarrhoea and Malnutrition in Children- A Study from Kishanganj District, Bihar. Jevol Med Dent Sci. 2014;3(4)3594-3599.

DOI: $\quad 10.14260 /$ jemds/2014/2326 [Crossref]
18. Kumar R, Borkar R. Magnitude and determinants of diarrhea among 0-6 year's children- a cohort study from central India. Int J Community Med Public Health. 2018;5(12)5246-52.

DOI: $\quad 10.18203 / 2394-6040$. ijcmph 20184798 [Crossref]

19. Kabhele S, New-Aaron M, Kibusi SM, Gesase AP. Prevalence and Factors Associated with Diarrhoea among Children between 6 and 59 Months of Age in Mwanza City Tanzania. J Trop Pediat. 2018;64(6)523-530.

DOI: $10.1093 /$ tropej/fmx109 [Crossref]

20. Nwaoha AF, Ohaeri CC, Amaechi EC. Prevalence of diarrhoea, and associated risk factors, in children aged 0-5 years, at two hospitals in Umuahia, Abia, Nigeria. Cuadernos de Investigación UNED. 2017;9(1)7-14.

DOI: $10.22458 /$ urj.v9i1.1672 [Crossref]

21. Musonda C, Siziya S, Kwangu M, Mulenga D. Factors associated with diarrheal diseases in under-five children- a case control study at arthur davison children's hospital in Ndola, Zambia. Asian Pacific J Health Sci. 2017;4(3)228-234.

DOI: $\quad 10.21276 /$ apjhs.2017.4.3.34 [Crossref] 